\title{
Intellectual Property Rights: Unlocking the Value of this New Asset Class Daniel J. Henry
}

\author{
"Next came the Patent laws. These began in England in 1624; and, in") \\ this country, with the adoption of our constitution. Before these, any \\ man might instantly use what another had invented; so that the \\ inventor had no special advantage from his own invention. The \\ patent system changed this; secured to the inventor, for a limited time, \\ the exclusive use of his invention; and thereby added the fuel of \\ interest to the fire of genius, in the discovery and production of new \\ and useful things.
}

Abraham Lincoln (1809-1865)

16th President of the United States

\begin{abstract}
Discussing the value of intellectual property (IP) has become a common theme in today's mainstream press and is now central to the business strategy of a growing number of technology companies, both large and small, domestically and internationally. This focus on IP and intellectual property rights (IPR) is a trend that has developed over the last several years as a result of a convergence of factors including the growth of the patent monetization industry, ongoing reforms to U.S. patent law, the emergence of China and other countries in the Far East as technology-production hubs, and the advocacy of the "knowledge-centric" economy. In this article, we look at the monetization of patents and the emergence of a vibrant industry based on IPR as a new and highly prized asset class.
\end{abstract}

\section{Introduction}

A patent is a form of intellectual property that consists of "a set of exclusive rights granted by a sovereign state to an inventor or the inventor's assignee for a limited period of time in exchange for the public disclosure of an invention" (http://wikipedia.org/wiki/Patent). National laws and international agreements govern how patents are granted and the extent of the rights conferred. Although details vary widely, patent rules generally require a patent application to describe the invention and to meet requirements, such as novelty and non-obviousness. Successful applicants are granted the right to prevent others from making, using, selling, or distributing the patented invention without permission.

Traditionally, the motivation for obtaining patents has been to protect an invention or innovation. This has been particularly true for startup enterprises. Filing for and securing patents around a product or service has been a necessary step to attracting investment capital. Potential investors did not necessarily understand the nuances of an invention, but they appreciated the exclusivity that a patent granted the holder.

In the last three decades, the driver for obtaining a patent has transformed. A growing number of inventors and companies have come to understand that a patent does not require the owner to practice the invention claimed. As manufacturing has been moved to the $\mathrm{Pa}$ cific Rim or other low-wage, limited-regulation venues, it has become impractical and uneconomical for many companies to build their own products or develop their own services. The more efficient approach is to recognize the value in your "intellectual capital" and license its use to corporations that have the infrastructure and means of distribution to more efficiently distribute the invention in the worldwide market. 


\section{Intellectual Property Rights: Unlocking the Value of this New Asset Class}

\section{Daniel J. Henry}

In this article, we begin with a brief snapshot of the present day's unprecedented level of IP transactions (i.e., the IP transaction cascade) that has cemented the shift in the role and value of IPR for today's businesses. We then explore historical paths that have led to this transformation and discuss the impact of new "patent paradigms" on the growth and sustainability of businesses today. Interspersed within the article are information boxes to help companies assess the potential value of IP (Box 1), assemble and manage a portfolio (Box 2), and balance the risks and rewards of monetizing their IPR (Box 3).

\section{The IP Transaction Cascade}

The focus on IP is a new trend that is perhaps best exemplified by the 2011 sale of the Nortel patent portfolio for an unprecedented $\$ 4.5$ Billion (http://wikipedia.org/ wiki/Nortel). Undertaken by a consortium of technology companies led by Apple, Ericsson and Microsoft, the purchase had an immediate catalyzing effect in the market. Noted investor Carl Icahn urged Motorola Mobility to investigate selling its patent portfolio. Within weeks, Google made a \$12.5-billion bid for the entire company (http://wikipedia.org/wiki/Motorola_Mobility), the presumed impetus being Motorola's portfolio of 17,000+ patents. Kodak engaged Lazard Ltd., the financial advisory and asset management company that had advised Nortel on its patent sale, to help with a potential sale of 1,100 imaging patents (http://tinyurl.com/d46oepq). This cascade of IP-based transactions would have been inconceivable even a decade ago. What has changed and how can IPR holders benefit from this transformation?

\section{Historical Paths: Corporations and Inventors}

To understand how to unlock the value of today's IPR, it is necessary to take a look back at the last several decades. The growing prominence of patents in the current business landscape is the result of the convergence of two distinct historical paths: one corporate-led, the other inventor-led.

From a corporate standpoint, IBM and the development of its intellectual property rights group in the late 1970s was pivotal to considering patents as assets with revenue potential. The break-up of "Ma Bell," the AT\&T-led system that was broken up into separate companies and regional phone systems by a U.S. Justice Department mandate in the early 1980s, is another important corporate example (http://wikipedia.org/wiki/ Bell_System_divestiture). Ma Bell owned a voluminous patent portfolio developed by its R\&D centre, Bell Labs. As a monopoly, Ma Bell was prohibited from generating value from its IPR. After its dismantling, AT\&T - and, later, a number of its spin-offs, notably Lucent Technologies - began securing patent licenses and royalties from companies in Silicon Valley, the Pacific Rim and Europe that were using Ma Bell's patented technology by incorporating it into their own products. These licensing agreements generated hundreds of millions of dollars.

Box 1. How to assess the potential value of IPR

The question of how the value of intellectual property can and should be measured is the subject of great interest and debate. A compelling, yet frustrating aspect of IPR is that there is no agreed upon process by which to quantify their value.

Differing technologies aside (e.g., for life sciences, physical sciences, medical devices, information technology), it is challenging within the same technology silo to properly value IPR. This is because each asset has unique features that make it patentable and distinct from its predecessors, at least theoretically. By focusing on the business objective of the exercise, the path ahead can be more easily defined.

The most straightforward method of gauging whether your IPR assets have value in the present or near term is to conduct a review to evaluate specific claims against the marketplace. Critical features of this assessment include the market, its size, and the technology; your IPR's competitive advantage or disruptive quality; and the impact of your IPR on the competition.
If you have the in-house capability to manage this review and have built your IPR in a pro-active and informed manner, this project should go quickly and yield positive results. Otherwise, engaging an outside professional is the logical next step. The optimum choice is a group or individual that brings expertise in your technology area, a broad understanding of the patent monetization process, and a willingness to create a program that is tailored to your specific needs. 


\section{Intellectual Property Rights: Unlocking the Value of this New Asset Class}

\section{Daniel J. Henry}

In terms of the impact of individual inventors on patent value, Jerome Lemelson's assertion licensing program, which was initiated in the mid-1980s, is compelling (http://wikipedia.org/wiki/Jerome_Lemelson). Lemelson was a "garage" inventor who developed a portfolio of patents that anticipated a number of technologies that later became widely deployed (e.g., bar codes). He exploited the rules of the U.S. patent system to generate a portfolio that grew in potential value as market adoption of his inventions increased. Lemelson partnered with Jerry Hosier, an astute attorney from Chicago, Illinois, to monetize his IPR assets. Together, along with an excellent support team, they proceeded to generate over $\$ 1$ billion dollars in settlements and licensing fees from companies that were infringing certain patents in the Lemelson portfolio. The success of the Lemelson program provided the impetus for other similarly situated inventors and patent owners to explore ways to generate revenues from their IPR. What these corporate and inventor programs had in common was success in generating revenues from their intangible assets. Patents were no longer just a plaque on the wall - they had become dynamic assets.

\section{IPR Emerges as a Distinct Asset Class}

The past decade has seen the monetization of patents expand and grow into a highly viable industry. New types of companies called non-practicing entities (NPEs) emerged. NPEs focused not on product development and commercialization, but on various aspects of IPR and how to foster and monetize these assets. Thought leaders in the intellectual property community and professional investors began discussing IPR as a distinct asset class. A number of articles posited how the value of trans-national corporations was mainly captured in their intangible assets (patents, copyrights, trade secrets and branding). Corporations established IPR groups as profit and loss centres, inspired by the licensing successes of IBM and AT\&T. This paradigm shift meant a company's IPR departments could no longer count on access to the "general treasury" to fund the development, prosecution, and maintenance of the company's patent portfolio. Instead they had to fund their activities by monetizing the IPR assets they had already developed. Companies that adapted and became successful at this new approach included GE, Honeywell, Siemens, and Philips.

Simultaneously, the number of NPEs defending their patent rights increased and began to coalesce around a specific Federal District Court in Eastern Texas. This court adapted specific rules of discovery for patent litig- ations, establishing a timeline that provided IPR owners with the certainty that their allegations of infringement would likely be heard by a jury within 12 to 16 months. This clear path to a resolution provided tremendous leverage to the NPE and produced settlement agreements without having to go to trial.

These agreements did not go unnoticed by financial investors. A number of private equity groups and larger hedge funds were intrigued by the opportunity IPR presented and created specific entities to invest in or purchase patent assets. These entities had differing investment philosophies, but each one centered on how to invest in and generate returns from IPR. Collectively, they attracted several billion dollars in investment capital.

This pool of capital had an immediate effect on the patent market. The baseline value of patents began to increase. Patents that were possibly infringed became valuable. Patents that had the potential to read across widely deployed technologies, such as semiconductors or wireless phones, were even more valuable. Patents with claims that read on specific industry standards, such as CDs, MPEG, JPEG, DVDs, and "802" CDMA technology, were considered the most valuable. Companies selling products or services based on industry standards had little choice but to negotiate a license with the IPR owner.

\section{Economic Downturn Creates New IPR Paradigms}

The global economic collapse of 2008 slowed the growth of the IPR asset market. The bubble that had developed in IPR valuation burst, and the market went into stasis for the next year. While a number of experts predicted the demise of the patent monetization market, an unexpected turn of events resulted in two paradigm shifts that minimized the effect of the downturn in the IPR market and bolstered large corporations and startups alike.

In the midst of the downturn, large corporations found themselves in need of more revenue. Management was under growing pressure to find additional revenue streams to bolster the bottom line and to boost cash reserves as the economy continued to spiral downwards. Prior to the downturn, many large companies had characterized IP licensing as an unfair and exploitive nuisance - one that cost them billions of dollars in legal fees. In the face of dwindling product revenue, however, they arrived at an unexpected solution to their fiscal challenge: monetize the largely fallow assets 


\section{Intellectual Property Rights: Unlocking the Value of this New Asset Class}

\section{Daniel J. Henry}

Box 2. How to assemble and manage a portfolio

Building, maintaining and monetizing IPR is as vital to the health of an organization as building products or services, and in a growing number of cases even more so. Therefore, when assembling a portfolio of intellectual property it is of paramount importance to establish and execute an effective process. This critical component of building a portfolio is often underestimated.

\section{Hardwire IPR into strategy and oper-} ations

A key pillar in developing your IPR is to engage knowledgeable professionals who are abreast with technology, industry, and patent monetization developments. Hiring an experienced IPR manager or Chief Intellectual Property Officer (CIPO) is a good first step. An internally managed program is optimal because the IPR manager is engaged in the daily operations of the business and compensation can be structured to reflect the development of the IPR program. As a member of the management team, an IPR manager is immersed in the company's strategy and operations, which ensures the IPR program is in lock-step with business objectives while at the same time supporting innovation.

Further, by interacting with the IPR development team, the IPR manager has access to broader ideas that can be maintained as potential trade secrets or that can be included in future prosecution filings. To expand the portfolio and enlarge its footprint, this internal data flow can be coupled with external research, including: monitoring the United States Patent and Trademark Office (http://uspto.gov) and other patent offices to stay abreast of patent filings in your technology space; reviewing technology and trade journals; and participating in standards organizations, to name a few.

\section{Build an expansive portfolio}

A balanced portfolio needs to have an accordion quality: narrow in places to protect and expansive elsewhere to capture broader technology developments. A company's management team must acknowledge that "their solution" may not be the one that wins. Having an expansive IPR platform provides the opportunity for another revenue channel as you license those IPR assets that capture the technology that has won the market. Contrary to common practice, by which technology companies focus only on their own innovations, in this authors' estimation, an IPR manager's responsibility should not only be to build the company's IPR portfolio, but also to guide the company so it does not fall afoul of another's IPR.

By staying attuned to industry and technology developments, your IPR manager can ensure capital is used most effectively to build your IPR portfolio and prevent pursuing a technological dead end, or worse, a future patent infringement lawsuit.

\section{Align with patent counsel}

The IPR manager will also need to engage with patent counsel. Prosecution of patents is as much art as science. Having a seasoned professional coordinating and guiding this process is a critical feature in creating IPR with the greatest potential value for your company. This individual or firm should be well versed in your technology area and able to navigate the bureaucracy of the various patent offices you will be filing in. In regards to foreign jurisdictions, this means having a network of local patent counsel in each jurisdiction that is just as capable in delivering positive results.

This is a key investment and requires the IPR manager to have a comprehensive global strategy. The IPR strategy should work seamlessly with a commercialization strategy. Is your company planning to sell in Europe, and if so, in which countries? Brazil is a growing market; will you need to file for protection there? In the Far East China and India are large potential markets but when it comes to IPR they are not the same: can you file in one and not the other? These issues need to be addressed as early in the process as possible so the proper human and capital resources will be dedicated.

In short, IPR management needs to be an integral part of corporate strategy; not an afterthought as it has historically been. And as such, it requires long-term capital investment which is the bedrock to a successful IPR program. 


\section{Intellectual Property Rights: Unlocking the Value of this New Asset Class}

\section{Daniel J. Henry}

of the company's IPR. These assets would be "found money" if properly deployed. Ironically, the very companies that had previously eschewed licensing the patented inventions of others' were now doing exactly that with their own IPR.

This new-found appreciation for IPR has not been restricted only to large patent holders. In the last three years, venture-backed startups have found that investment capital has dried up. Experienced startup executives, along with certain investors and IP professionals, have realized that a viable response to this challenge is to license their existing IPR to fund ongoing innovation. They have recognized that a company's IPR assets, even those that are nascent in their development, provide them with an opportunity to raise additional capital to support their ultimate goal of commercial success. Raising additional capital by licensing or divesting their IPR allows them to avoid the high price that an additional round of investment (if they can secure one) would demand.

\section{Conclusion}

There is no question that the industry is in the midst of a continuing evolution. How inventors and corporations think about their IPR assets and use the means available to unlock their value is a crucial factor to sustaining growth and fuelling innovation. The World Intellectual Property Organization (WIPO; http://wipo.int) has just released a report entitled World Intellectual Property Report: The Changing Face of Innovation

Box 3. Balancing the risks and rewards

Every IPR owner has a legal right to optimize the value of their assets. A complex undertaking, the monetization of IPR needs to be carefully considered. An IPR monetization program can be structured to have multiple options to reflect a company's risk profile.

The least risky program is to identify non-core or redundant assets and divest them. This can be done internally or through an IP broker. If engaging a broker, it is important to work with one who has an established reputation, a record of success, and works on a "success fee" basis. A successful sale will generate revenue and relieve the company of costs associated with maintaining the non-core or redundant IP.

The next option is to develop a licensing program. This can be done in-house, which would require hiring experienced personnel, or can be outsourced to a company that specializes in patent licensing. An outsourced program can be structured on a pure contingent basis or a hybrid fee structure. It can include an upfront or hourly fee with a cap and a success component.

The third option to monetize your IPR is to conduct an assertion licensing program. This requires filing a lawsuit in the proper venue against a company or companies who are using your IPR without a license. As with the other options, a thorough review and plan of action needs to be generated prior to initiation. The review should identify the risks, which will include potential counterclaims filed against your company and possibly broader consequences to your commercial business, such as some customers or suppliers electing to no longer do business with you.

In certain cases, assertion licensing may be a "bet the company" tactic necessitated by the severe negative consequences that the infringement of your IPR has produced. In pursuing this course, a company will need to engage with an outside legal counsel that spe- cializes in IP litigation. A crucial factor will be under what structure you engage counsel - full fee, a partial contingency, or full contingency. The factors guiding this choice will include the company's cash on hand, future revenue flow, and aligning risk. Another possibility is to engage with a professional assertion licensing company that brings expertise, capital, and reputation.

Finally, you can retain the IPR within the company and have outside professionals manage its licensing program. The risk in this arrangement is that the company will be exposed to potential counterclaims, but if fully litigated, the infringer could be enjoined from selling any infringing product or service. This creates tremendous leverage for the IPR owner and would likely produce optimal results.

Monetizing IPR is not an easy matter. When balanced against the investment required to create these valuable assets in the first place, IPR are well worth defending. 


\section{Intellectual Property Rights: Unlocking the Value of this New Asset Class}

\section{Daniel J. Henry}

(http://tinyurl.com/7fuv445), which indicates that worldwide royalty and licensing revenue from IPR has grown from $\$ 27 \mathrm{~B}$ in 1990 to $\$ 180 \mathrm{~B}$ in 2009 . This is nearly a sixand-a-half-fold increase and should serve as a beacon for all IPR owners.

The path to growing a business has expanded beyond the single dimension of introducing a product or service into the marketplace. The past two decades has crystalized the need for a multi-faceted approach to growing a successful business and leveraging IPR assets are an essential component. The following four success factors are important considerations as companies seek to maximize the value of their IPR:

1. Defining an IPR development program. New and growing businesses need to have a defined and strategic IPR development program that covers patents, brands, trade secrets, and business intelligence. How these assets are developed, maintained, protected, and monetized can no longer be done on an ad hoc basis.

2. Investing in seasoned management. Hiring an IPR Manager or Chief Intellectual Property Officer (CIPO) should be an early development when assembling a management team. This individual should have a track record of successfully building an IPR position that supports the business while simultaneously covering the larger market.

3. Funding for the long term. Designating sufficient capital for IPR development is another critical step and should not be considered on an annual basis but on an extended timeline. IPR takes several years to mature and running short of capital three or four years out may result in cannibalization of the IPR program, materially reducing its value and the value of the company.

4. Enlisting expert advisors. Identifying the right external IPR advisors - those who have extensive experience with the relevant technology area, will be essential in avoiding any major pitfalls. Globalization and the rapid advancement of technology demands rigid discipline and vision when it comes to IPR assets.

Companies who innovate need to recognize that IPR assets are the natural outgrowth of their intellectual capital and stand as a testament to the company's value in the global marketplace. Failure to understand, nurture, and monetize IPR will lead to an outcome most recently exhibited in the Nortel bankruptcy where founders and shareholders alike were left wondering "if only...."

\section{About the Author}

Daniel J. Henry is Vice President, Business Development with WiLAN Inc., Canada's largest publicly traded IP licensing firm. A seasoned IP executive, he has extensive experience in corporate and IP law and business development. Before joining WiLAN Inc., Mr. Henry held the position of Senior Vice President with ICAP Patent Brokerage, where he advised clients on the sale and acquisition of valuable IP assets. Prior to ICAP, he was a Partner with Altitude Capital Partners, where he conceived and executed the firm's business development program and strategic relationships with corporate IP holders and other IP professionals. Mr. Henry is a practiced speaker on IP and value generation at conferences internationally and has been recognized by Intellectual Asset Magazine as one of the top 250 IP strategists in the world for the past three years.

Citation: Henry, D.J. 2011. Intellectual Property Rights: Unlocking the Value of this New Asset Class. Technology Innovation Management Review. December 2011: 23-28. (cc) BY 